\title{
High prevalence of cognitive impairment among students near mount Merapi: a case study
}

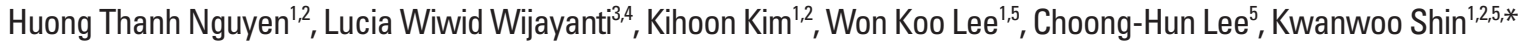 \\ 'Department of Chemistry, Sogang University, Seoul, Korea \\ ${ }^{2}$ Institute of Biological Interfaces, Sogang University, Seoul, Korea \\ ${ }^{3}$ Department of Chemistry Education, Universitas Santa Dharma, Yogyakarta, Indonesia \\ ${ }^{4}$ Department of Chemistry, Universitas Gadjah Mada, Yogyakarta, Indonesia \\ ${ }^{5}$ Center for Science and Technology International Cooperation, Sogang University, Seoul, Korea
}

This descriptive, cross-sectional study illustrates the high prevalence of intellectual impairment among students at the Kanisius Prontakan primary school near Mt. Merapi, one of the most active volcanic mountains in Indonesia. To determine the possible cause of these abnormal cognitive impairments, we considered and investigated the threats to society and the environment of the frequent volcanic eruptions, as well as the effects of malnutrition due to extreme poverty, in that area. The results showed that intellectual impairment and stunting were remarkably common among the students, with $10.7 \%$ of the students showing sigma of intellectual impairment and $96.4 \%$ showing signs of stunting.
No noticeable chemical problems due to the volcanic activity were found in the drinking water, and no causes of such disorders other than poor nutrition due to poverty were found. Nevertheless, our results provide information on the high prevalence of health problems being experienced by children living in one of the most isolated and underdeveloped volcano mountain areas in Indonesia and draws attention to the severe effects of malnutrition on the development of those children.

Keywords: Impaired cognition, Stunting, Malnutrition, Intellectual disabilities

\section{INTRODUCTION}

Early childhood is known to be an essential period for the development of cognition and health in humans. Children exposed to malnutrition or environmental toxicity are susceptible to diseases (pneumonia, severe infections, etc.) and have a high mortality rate (Heikens et al., 2008; Newton et al., 2008). In developing countries, many children suffer from malnutrition, as measured by stunting, but this problem is often disregarded in those societies. Estimates for 2,000 suggested that $29.8 \%$ of the children in developing countries suffered from malnutrition. This malnutrition is also known to have a great influence on mental cognitive ability, and research has reported a strong association between stunting and cognitive performance (e.g., memory disorders, distractibility, and confusion) among children of school-going age (de Onis and Blössner, 2003). For examples, in a study involving
1,674 children in Peru, a significant association was found between stunting and impaired cognitive skills (Crookston et al., 2011). In another study, lack of proper nutrients was found to have affected the normal growth of children who had been malnourished during early childhood (Mendez and Adair, 1999), drawing attention to the recognition and the prevention of early stunting in children in order to improve their cognition. In addition to malnutrition, however, many researchers have reported other factors that might be significantly related to cognitive impairment among children in developing countries; for example, Warsito et al. (2012) analyzed several variables that were thought to have an impact on children's cognition, including mother's education, income per capita, mother's knowledge of good nutrition, participation in early childhood education, psychosocial stimulation, and nutritional status. That no single factor is fully responsible for cognitive development in young children is now a widely
${ }^{\star}$ Corresponding author: Kwanwoo Shin (D https://orcid.org/0000-0002-7563-8581 Department of Chemistry and Institute of Biological Interfaces, Sogang University, 35 Baekbeom-ro, Mapo-gu, Seoul 04107, Korea

Tel: +82-2-705-8441, Fax: +82-2-701-0967, E-mail: kwshin@sogang.ac.kr Received: May 25, 2018 / Accepted: June 11, 2018
This is an Open Access article distributed under the terms of the Creative Commons Attribution Non-Commercial License (http://creativecommons.org/licenses/by-nc/4.0/) which permits unrestricted non-commercial use, distribution, and reproduction in any medium, provided the original work is properly cited. 


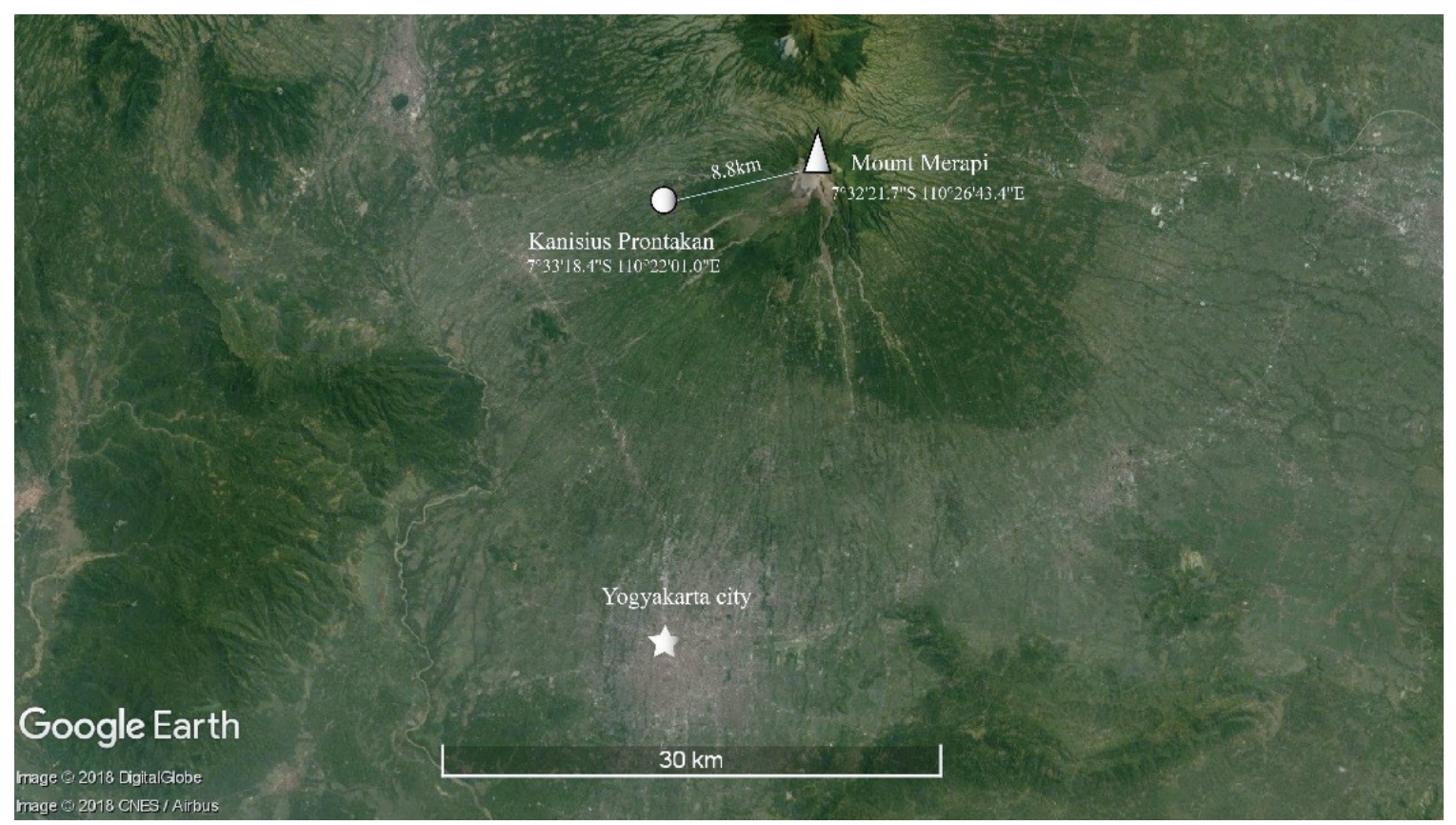

Fig. 1. The location of Yogyakarta city (star) and the location of the Kanisius primary school (circle, $\left.7^{\circ} 33^{\prime} 18.5^{\prime \prime} \mathrm{S} 110^{\circ} 22^{\prime} 00.8^{\prime \prime} \mathrm{E}\right)$ from Mount Merapi (triangle, $7^{\circ} 32$ '21.8'S $\left.110^{\circ} 26^{\prime} 43.5^{\prime \prime} \mathrm{E}\right)$.

accepted premise.

Like many other developing countries, poor nutrition among children is a major problem in Indonesia; In 1999, research on 163,986 children below the age of 5 years in Indonesia revealed that about $28.5 \%$ of those children were underweight (Waters et al., 2004). A recent study in Indonesia in 2007 involving 1,311 children with ages from 2 to 5 years reported that $21.4 \%$ of the children were underweight and that $36.7 \%$ were stunted (Rachmi et al., 2016). In spite of the sustained economic growth and progress in reducing poverty in modern Indonesia, the status of child nutrition continues to remain a critical social issue, especially in socially underprivileged communities; however, other socio-economic factors, including mother's education, water and sanitation conditions, household poverty, and access to healthcare, also have great impacts on stunting and cognitive development in children.

Mount Merapi is a volcanic mountain peak located near the center of the island of Java, Indonesia, about $32 \mathrm{~km}$ north of Yogyakarta. It rises to 2,911 meter and has steep slopes with dense vegetation. It is regarded as the most active volcano among Indonesia's 130 active volcanoes. A series of eruptions of the volcano in 2010, which included pyroclastic flows, which are clouds of superheated gases and incandescent solid particles, caused 141 deaths, 453 injuries, and the evacuation of 278,000 people. The Kanisius is a primary school with 56 students, which, as marked in Fig. 1, is located in Prontakan, the closest village to that volcano, being about $8.8 \mathrm{~km}$ from its peak. After its eruption in 2010, the village near the school was fully covered with volcanic rocks and ashes. The inhabitants of this village, which remains one of the most underprivileged communities in Indonesia, have a socially and environmentally difficult life due to frequent volcanic disasters. Indeed, mental cognitive impairment and extreme growth disorders have been identified in the children of this village. This led us to question how the health of the children in the village might have been affected by toxins in the environment due to volcanic activity. Therefore, this research, a case study, sought to contribute to the literature on the impacts of child malnutrition by exploring the relationship between stunting in early childhood and any serious environmental problems; to do this, we observed the mental and physical health problems among the children at the Kanisius primary school.

\section{MATERIALS AND METHODS}

This cross-sectional study, which was conducted in 2017, involved 56 students at the Kanisius primary school in Prontakan, Indonesia. Its geographical location is shown in Fig. 1. Our study involved 24 male (42.9\%) and 32 female students (57.1\%), with ages ranging from 7 to 14 years. All students who were enrolled 
at the Kanisius school when this study took place were eligible to be included in this research. Of the eligible students, those who had high rates of absences or who had declined inclusion in the research were excluded.

Height and weight were measured using a standing meter stick and a medical scale, respectively. The body mass index (BMI) for age and the height for age of 56 students were calculated and categorized by using the $Z$-score according to World Health Organization (WHO) growth reference data for children and adolescents 5-19 years of age (de Onis and Blössner, 2003). Weight for age data was obtained for only 44 students. This indicator does not apply to students entering puberty, because the increase in body weight is not necessarily related to height (World Health Organization [WHO], 2009).

To evaluate the cognitive ability of the student, we used the intelligence quotient (IQ) score as an indicator. We compared students' performance on a standardized IQ test by converting their performances into percentiles or into a score using a normative average of 100 with a standard deviation (SD) of 15 . In our study, IQ scores were categorized by using Raven's Colored Progressive Matrices (RCPM) (Raven, 1986). Raw scores from the individual Raven's tests were adjusted by age into percentile according to the RCPM manual and were categorized as follow (Raven et al., 1998):

- Intellectually superior: $\geq 95$ th percentile for children of that age group,

- Above average in intellectual capacity: $\geq 75$ th and $<95$ th percentile for that age group,

- Intellectually average: $\geq 25$ th and $<75$ th percentile for that age group,

- Below average in intellectual capacity: $\geq 5$ th and $<25$ th percentile for that age group,

- Intellectually impaired: $<5$ th percentile for that age group.

A questionnaire was designed to collect information regarding family history, source of drinking water, and factors associated with the parent's occupation. Parent or family members (older than 18 years of age) who were living in the same house with the students were invited to the school. Questionnaires were completed based on the instructions and/or direct interviews given by well-trained interviewers fluent in Indonesia. All of the people who provided information for this study gave verbal informed consent; in many cases, written consent could not be obtained due to the high rate of illiteracy among the interviewees.

Drinking water was sampled at three different sites. Sample one was taken from the river near the school, which was said to be the most common source of water for the villagers, sample two was taken from the water source at the school where the students were studying, and sample three was from the church near the school. Drinking water samples from those sites were analyzed for 13 chemicals that have been reported to be related to health when absorbed in large amounts. The amount of each element was measure in $\mathrm{ng} / \mathrm{mL}$, and the results were compared with the standards for drinking water published by the WHO, Geneva, 1993 (mg/L) (WHO, 2017a). All samples were collected using new, sterilized plastic containers, after which they were taken to Korea, where they were analyzed using atomic absorption spectrometry to quantify the concentration of each of the 13 elements in the water samples. An inductively coupled plasma - mass spectrometer (NexION 300 ICP-MS, PerkinElmer Inc., Hopkinton, MA, USA) and an inductively coupled plasma - optical emission spectrometer (Optima 8300 ICP-OES, PerkinElmer Inc.) were used for the measurements.

IBM SPSS Statistics ver. 22.0 (IBM Co., Armonk, NY, USA) was used for data entry and data analysis. Due to small sample size ( $n=56$ ), Fisher exact test was employed to examine the significance of the association between the different classifications. The nutrition status and the $Z$-score were determined using WHO AnthroPlus software (V1.0.4 for personal computers), which was developed to assess the growth of the world's children and adolescents. A $P$-value less than 0.05 was used as the cutoff for significance.

\section{RESULTS}

\section{Characteristics of the studied population}

In 2017, this school had more female (57.1\%) than male students (42.9\%) (Fig. 2A). Students in grades 3 and 4 made up $50 \%$ (28 students put of a total of 56) of the study sample whereas the numbers of students in grade 5 and 6 were relatively small (Fig. 2B). For parents' occupation, farming was the most prevalent, with $53.6 \%$ and $58.9 \%$ of the fathers and the mothers, respectively, being involved in that vocation; $19.6 \%$ and $25 \%$ of the fathers and the mothers, respectively, reported working as laborers. We noted that the villagers often held several jobs at the same time to earn a living; for example, while they were farming, many of them also collected black sand and volcanic rocks for construction. Only about $10 \%$ of the mothers stayed at home as housewives. A local stream nearby (Nangdong) provided water to one-third of the people in the study; however, many people interviewed stated that they used more than one source of water for daily life (Table 1). 

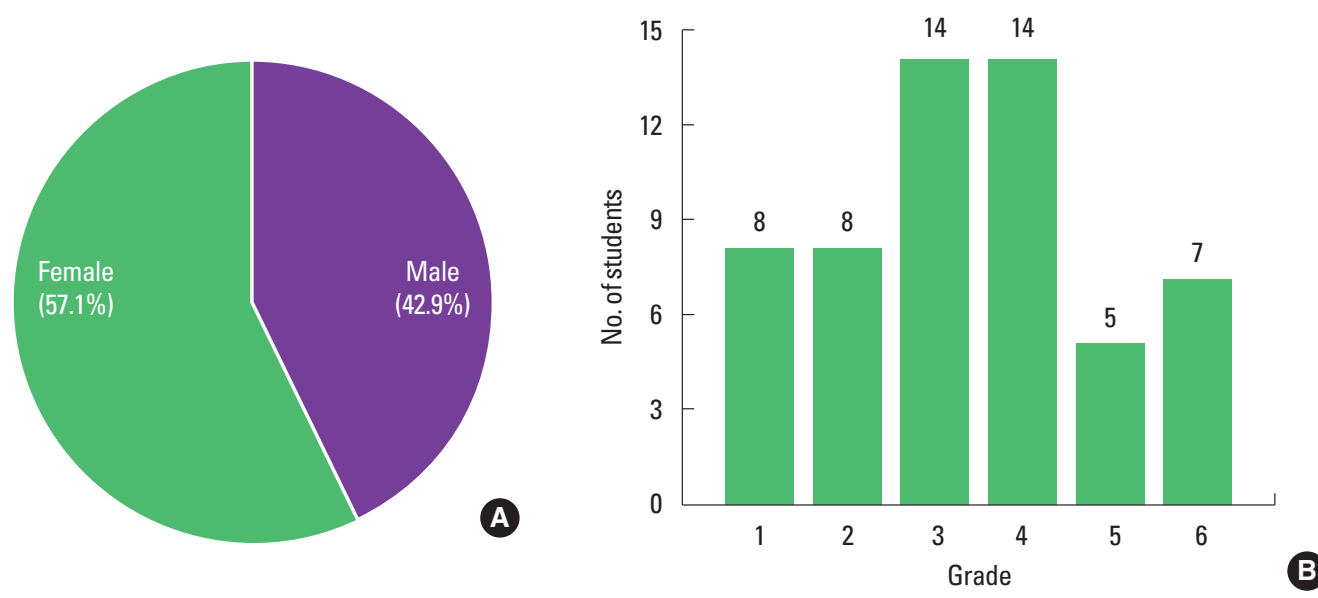

Fig. 2. Characteristics of the studied population: gender of participants (A) and number of students (B) in each grade from 1 to $6(n=56)$.

Table 1. Characteristics of the studied population $(n=56)$

\begin{tabular}{lc}
\hline Characteristic & Proportion (\%) \\
\hline Father's occupation & 53.6 \\
Farmer & 25.0 \\
Laborer & 5.4 \\
Deceased & 16.1 \\
Other & \\
Mother's occupation & 58.9 \\
Farmer & 19.6 \\
Laborer & 10.7 \\
Housewife & 10.7 \\
Other & \\
Main source of drinking water (small river/stream) & 33.9 \\
Ngandong (local river) & 8.9 \\
Blongkeng (local stream) & 14.3 \\
Keji (local stream) & 42.9 \\
Other & \\
\hline
\end{tabular}

\section{IQ scores and related factors}

Our IQ results revealed that $19.6 \%$ of the students were below average intelligence and that $10.7 \%$ were intellectually impaired (Fig. 3). Several factors that might have been the causes of this cognitive impairment, such as family psychiatric and goiter history, birth history, infection during pregnancy, head trauma, and main source of drinking water, were investigated. Among the 56 children, $14.3 \%$ were born with the use of a C-section or vacuum or forceps, which are common risk factors for head trauma during birth (Table 2). Of the students, $8.9 \%$ had a parent or a sibling with a psychiatric disorder according to the perception of the interviewed person, and $5.3 \%$ had at least one family member with visible goiter. Especially, signs of maternal infection were very

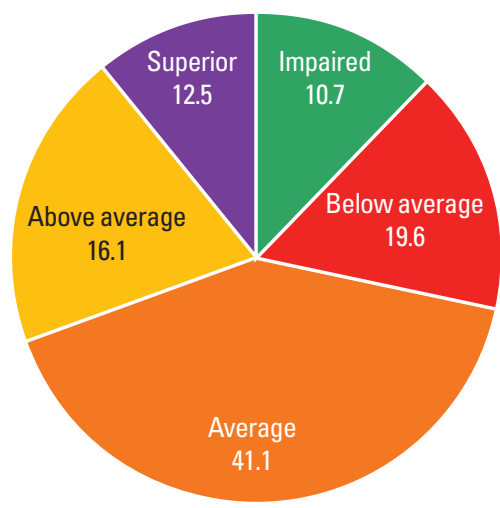

Fig. 3. Intelligence quotient percentiles of students $(n=51)$ at the Kanisius school as measured by using Raven's Colored Progressive Matrices.

common, accounting for $60.7 \%$ of the 56 recorded cases of infections. Moreover, $69.6 \%$ of the children had been infected with bronchitis at least once in their lives and/or with measles, mumps, or chicken pox. However, Fisher exact test showed no statistical difference of IQ scores among the groups (Table 2).

As can be seen, students in grades 1-2 and 5-6 showed higher proportions of impaired intelligence (5.4\% in both groups) than students in grades $3-4(P<0.05)$ (Table 2). Additionally, 96.4\% of the students were shorter than the WHO's standard for children and adolescents aged 5-19. About $14.3 \%$ of the students aged 6-10 years were underweight $(<-2 \mathrm{SD})$. The overwhelming shortness among the students caused both the BMI for age and the weight-to-height ratio to be very high (Table 3).

Because chemical exposure could be a cause of low IQ and stunting, we collected and analyzed water samples taken from three sources of water in the region to determine if the low IQ and stunting might be related to contaminants in the drinking water. 
Table 2. Results showing the effects of several factors on 10 test performance $(n=56)$

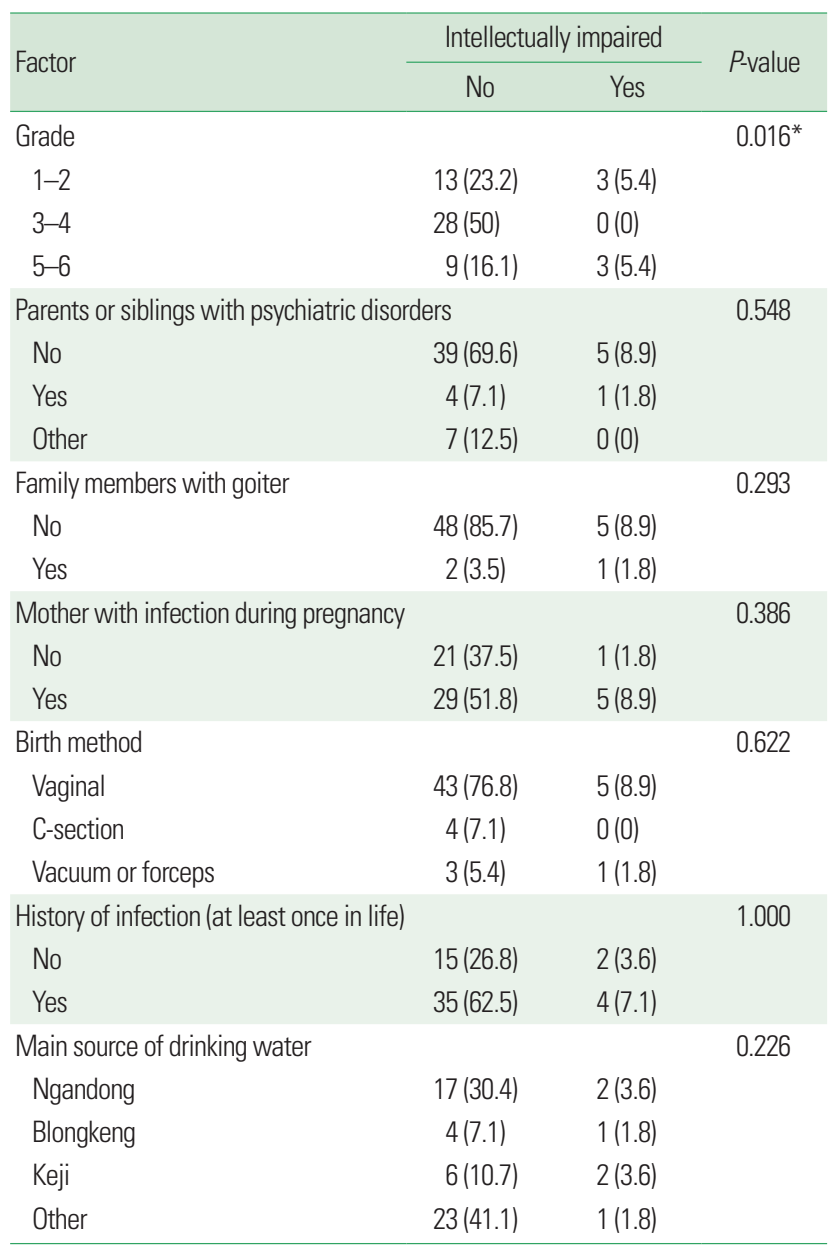

Values are presented as number (\%).

${ }^{*} P<0.05$, Fisher exact test.

The analysis showed that the concentrations of all the chemicals detected in the water samples from the three sources fell within the safe range as defined by the WHO (Table 4). Calcium and magnesium seemed to be high, but the WHO provides no guidelines for these chemicals because their effects on human health have not been recorded (Rapant et al., 2017).

\section{DISCUSSION}

Our report reveals that a significantly high number of students in the underdeveloped region of Prontakan in Indonesia are suffering from intellectual impairment. The IQ for Indonesia was estimated to be approximately 87 in the 2010 data of Lynn and Meisenberg (2010). Other research on primary school students (6 to 10 years of age) in Bali, Indonesia, reported an average IQ of 84
Table 3. Nutrition status of the subjects

\begin{tabular}{lc}
\hline Variable & No. $(\%)$ \\
\hline Weight for age $(n=44)$ & \\
Very low $(<-3 \mathrm{SD})$ & $2(3.6)$ \\
Low $(<-2 \mathrm{SD})$ & $6(10.7)$ \\
Height for age $(\mathrm{n}=56)$ & \\
Very low $(<-3 \mathrm{SD})$ & $53(94.6)$ \\
Low $(<-2 \mathrm{SD})$ & $1(1.8)$ \\
BMl for age $(\mathrm{n}=56)$ & \\
Severe thinness $(<-3 \mathrm{SD})$ & $1(1.8)$ \\
High w/h $(>+1 \mathrm{SD})$ & $19(33.9)$ \\
Very high $\mathrm{w} / \mathrm{h}(>+2 \mathrm{SD})$ & $36(64.3)$
\end{tabular}

SD, standard deviation; BMl, body mass index; w/h, weight/height.

Table 4. Results of the drinking water analyses

\begin{tabular}{lrrrr}
\hline $\begin{array}{c}\text { Element (symbol, } \\
\text { atomic number) }\end{array}$ & $\begin{array}{c}\text { River } \\
(\mathrm{ng} / \mathrm{mL})\end{array}$ & \multicolumn{1}{c}{$\begin{array}{c}\text { School } \\
(\mathrm{ng} / \mathrm{mL})\end{array}$} & $\begin{array}{c}\text { Church } \\
(\mathrm{ng} / \mathrm{mL})\end{array}$ & \multicolumn{1}{c}{$\begin{array}{c}\text { WHO } \\
(\mathrm{mg} / \mathrm{L})\end{array}$} \\
\hline Mercury (Hg, 202) & 0.052 & 0.046 & 0.034 & 0.001 \\
Lead (Pb, 208) & 0.008 & 0.058 & 2.204 & 0.01 \\
Arsenic (As, 75) & 0.439 & 0.772 & 0.538 & 0.01 \\
Cadmium (Cd, 114) & 0.007 & 0.008 & 0.012 & 0.003 \\
Aluminum (Al, 27) & 1.886 & 2.582 & 1.031 & 0.2 \\
Barium (Ba, 138) & 6.491 & 8.126 & 7.849 & 0.3 \\
Selenium (Se, 82) & 0.721 & 0.726 & 0.402 & 0.01 \\
Zinc (Zn, 30) & $\mathrm{ND}$ & 465.485 & $1,120.977$ & 3 \\
Chromium (Cr, 52) & $\mathrm{ND}$ & $\mathrm{ND}$ & $\mathrm{ND}$ & 0.05 \\
Iron (Fe, 56) & 11.048 & 14.892 & 10.270 & 0.2 \\
Copper (Cu, 63) & 0.140 & 0.411 & 0.442 & 2 \\
Magnesium (Mg, 12) & $4,185.525$ & $6,670.463$ & $7,154.847$ & - \\
Calcium (Ca, 20) & $25,459.041$ & $36,172.913$ & $25,715.348$ & - \\
\hline
\end{tabular}

WHO, World Health Organization; ND, nondescriptive values (lower than the detection range).

(Rindermann and te Nijenhuis, 2012). Such IQ data show that the average IQ of an Indonesian child is, in general, lower than that of children in many other Asian countries, such as Korea, Vietnam and China (Lynn and Meisenberg, 2010).

Environmental exposure to toxins, for example, mercury and lead, has been reported to increase the risk of IQ impairment. Moreover, the eruption of Mt. Merapi in 2010 led to the formation of a number of environmental chemicals that potentially could affect the health and mental development of the children in this area (Hlodversdottir et al., 2016; Zeballos et al., 1996). Most of these toxins accumulate in soil and are then transferred to food and water (Liu et al., 2010). For that reason, we determined the concentrations of several chemicals in samples taken from the main sources of drinking water for the villagers. However, no 
chemicals were found to have levels higher than the standards for drinking water provided by the WHO (WHO, 2017b). In addition to investigation of the drinking water, we also collected and analyzed data on other factors that might have affected the children's cognition, such as medical and trauma history, goiter, nutritional status, and the family member with a psychiatric disorder. We found that the mothers of more than half of the children in this area might have had an infection during the prenatal period. In fact, their mothers had experienced symptoms such as fever, diarrhea or swollen glands when they were pregnant; this indicates that those mothers might have had a viral or bacterial infection during pregnancy. Whether or not the babies presented with symptoms of infection, such as jaundice, fever, coughing poor appetite, etc., could not be determined due to lack of awareness of the mothers. Nevertheless, congenital infection might have severe consequences, including cognitive impairment (Cannon, 2009). This is an important finding because a study on the nutritional status of Indonesian infants showed that prenatal factors had more impact on their growth than postnatal events (Schmidt et al., 2002). These observations might result from poor healthcare and poor sanitation systems, low awareness of residents about possible factors that affect their health, and especially the alarming environmental situation in this area near an active volcano. Although no significant relationship between the above factors and the development of cognition in the investigated children was observed, literature reviews provide strong evidence that the simultaneous effects of different factors might have a great impact (Dickerson and Popli, 2016).

From our investigation, we found an excessively high rate of stunting among the students, with most of them being severely stunted, which has never been observed in other regions in Indonesia (Chirande et al., 2015; de Onis and Blössner, 2003; Dearden et al., 2017; Tiwari et al., 2014; WHO, 2017b). For example, in a study involving 1,366 children from three districts in the country, the incidences of stunting and severe stunting were $28.4 \%$ and $6.7 \%$, respectively, which are much lower than our observations in Pronkatan (Torlesse et al., 2016). Another study in 2009 that assessed the proportion and the determinants of stunting and severe stunting among 0 - to 5 -year-old children in North Maluku Province reported 29\% incidence of stunted children (Ramli et al., 2009). Similarly, in a previous study in the Village of Babakan, West Java, the data on nutritional status revealed that a total of $24.1 \%$ of the children were underweight and wasted and that $19 \%$ were stunted or severely stunted (Warsito et al., 2012). These results highlight that malnutrition, both before and after birth, greatly influences the intelligence of school-age children ( $\mathrm{Li}$ et al., 2016). The prevalence of stunting among students at the Kanisius primary school was very high compared with the values published in many other reports on rural areas around Indonesia (Torlesse et al., 2016; Warsito et al., 2012), stunting in childhood is known to lead to a higher risk of obesity in later life, which is a double burden in many countries (Tzioumis and Adair, 2014). This can be seen in our results, where many students had elevated weights, but smaller heights, resulting in the BMI for age being $>2$ SD. Thus, although our results found insignificant differences of IQ between the stunted group and the other groups, the early and prolonged effects of malnutrition might be contributing to the high prevalence of below-average IQ in the studied community.

Note that the present study has some limitations. Due to the overwhelming proportion of stunting and the small population that could be included in the research, conditions were not favorable for statistically observing the relationship between nutritional status and the IQ of the students in this region. Moreover, getting information from the parents was difficult owing to their low awareness of personal healthcare. Information on medical and trauma history was also limited as most families did not use medical services for nonsevere diseases. The language barrier was another difficulty when trying to design a more detailed questionnaire. Because the area of our study is dangerously near an active volcano that had erupted seven years earlier, many people may have migrated in and out of this region, which may have had an impact on the prevalence of health problems that we noted.

In summary, from our field research, we found significantly high rates of intellectual impairment and stunting among students in the Kanisius primary school at Prontakan. Although the prevalence of these health problems was high, no direct causes could be found in this research. Furthermore, from among many socio-economic factors, such as family psychiatric and goiter history, birth history, infection during pregnancy, head trauma, and main source of drinking water, we were unable to associate any of these factors with the health problems. Nevertheless, the results from our study should provide valuable information for use in local health promotion programs and for further studies evaluating the effects of volcanoes on the health of the residents in the surrounding communities.

\section{CONFLICT OF INTEREST}

No potential conflict of interest relevant to this article was reported. 


\section{ACKNOWLEDGMENTS}

This work was supported by the Leading University Project for International Cooperation (2015H1A7A2A02037456,) and Basic Science Research Program (2018R1A6A1A03024940) funded by the National Research Foundation, Korea.

\section{REFERENCES}

Cannon MJ. Congenital cytomegalovirus (CMV) epidemiology and awareness. J Clin Virol 2009;46 Suppl 4:S6-10.

Chirande L, Charwe D, Mbwana H, Victor R, Kimboka S, Issaka AI, Baines SK, Dibley MJ, Agho KE. Determinants of stunting and severe stunting among under-fives in Tanzania: evidence from the 2010 cross-sectional household survey. BMC Pediatr 2015;15:165.

Crookston BT, Dearden KA, Alder SC, Porucznik CA, Stanford JB, Merrill RM, Dickerson TT, Penny ME. Impact of early and concurrent stunting on cognition. Matern Child Nutr 2011;7:397-409.

de Onis M, Blössner M. The World Health Organization global database on child growth and malnutrition: methodology and applications. Int J Epidemiol 2003;32:518-526.

Dearden KA, Schott W, Crookston BT, Humphries DL, Penny ME, Behrman JR; Young Lives Determinants and Consequences of Child Growth Project Team. Children with access to improved sanitation but not improved water are at lower risk of stunting compared to children without access: a cohort study in Ethiopia, India, Peru, and Vietnam. BMC Public Health 2017;17:110.

Dickerson A, Popli GK. Persistent poverty and children's cognitive development: evidence from the UK Millennium Cohort Study. J R Stat Soc Ser A Stat Soc 2016;179:535-558.

Heikens GT, Bunn J, Amadi B, Manary M, Chhagan M, Berkley JA, Rollins N, Kelly P, Adamczick C, Maitland K, Tomkins A; Blantyre Working Group. Case management of HIV-infected severely malnourished children: challenges in the area of highest prevalence. Lancet 2008;371: 1305-1307.

Hlodversdottir H, Petursdottir G, Carlsen HK, Gislason T, Hauksdottir A. Long-term health effects of the Eyjafjallajökull volcanic eruption: a prospective cohort study in 2010 and 2013. BMJ Open 2016;6:e011444.

Li C, Zhu N, Zeng L, Dang S, Zhou J, Yan H. Effect of prenatal and postnatal malnutrition on intellectual functioning in early school-aged children in rural western China. Medicine (Baltimore) 2016;95:e4161.

Liu Y, McDermott S, Lawson A, Aelion CM. The relationship between mental retardation and developmental delays in children and the levels of arsenic, mercury and lead in soil samples taken near their mother's residence during pregnancy. Int J Hyg Environ Health 2010;213:
116-123.

Lynn R, Meisenberg G. National IQs calculated and validated for 108 nations. Intelligence 2010;38:353-360.

Mendez MA, Adair LS. Severity and timing of stunting in the first two years of life affect performance on cognitive tests in late childhood. J Nutr 1999;129:1555-1562.

Newton SM, Brent AJ, Anderson S, Whittaker E, Kampmann B. Paediatric tuberculosis. Lancet Infect Dis 2008;8:498-510.

Rachmi CN, Agho KE, Li M, Baur LA. Stunting, underweight and overweight in children aged 2.0-4.9 years in indonesia: prevalence trends and associated risk factors. PLoS One 2016;11:e0154756.

Ramli, Agho KE, Inder KJ, Bowe SJ, Jacobs J, Dibley MJ. Prevalence and risk factors for stunting and severe stunting among under-fives in North Maluku province of Indonesia. BMC Pediatr 2009;9:64.

Rapant S, Cvečková V, Fajčíková K, Sedláková D, Stehlíková B. Impact of calcium and magnesium in groundwater and drinking water on the health of inhabitants of the Slovak Republic. Int J Environ Res Public Health 2017;14(3):pii:E278.

Raven J, Raven JC, Court JH. Manual for raven's progressive matrices and vocabulary scales: section 2 : coloured progressive matrices. Oxford: Oxford Psychologists Press; 1998.

Raven JC. Coloured progressive matrices: sets A, AB, B. London: Lewis; 1986.

Rindermann H, te Nijenhuis J. Intelligence in Bali - A case study on estimating mean IQ for a population using various corrections based on theory and empirical findings. Intelligence 2012;40:395-400.

Schmidt MK, Muslimatun S, West CE, Schultink W, Gross R, Hautvast JG. Nutritional status and linear growth of Indonesian infants in west java are determined more by prenatal environment than by postnatal factors. J Nutr 2002;132:2202-2207.

Tiwari R, Ausman LM, Agho KE. Determinants of stunting and severe stunting among under-fives: evidence from the 2011 Nepal Demographic and Health Survey. BMC Pediatr 2014;14:239.

Torlesse H, Cronin AA, Sebayang SK, Nandy R. Determinants of stunting in Indonesian children: evidence from a cross-sectional survey indicate a prominent role for the water, sanitation and hygiene sector in stunting reduction. BMC Public Health 2016;16:669.

Tzioumis E, Adair LS. Childhood dual burden of under- and overnutrition in low- and middle-income countries: a critical review. Food Nutr Bull 2014;35:230-243.

Warsito O, Khomsan A, Hernawati N, Anwar F. Relationship between nutritional status, psychosocial stimulation, and cognitive development in preschool children in Indonesia. Nutr Res Pract 2012;6:451457.

Waters H, Saadah F, Surbakti S, Heywood P. Weight-for-age malnutrition 
in Indonesian children, 1992-1999. Int J Epidemiol 2004;33:589-595.

World Health Organization. Guidelines for drinking-water quality, 4th edition, incorporating the 1st addendum. Geneva: World Health Organization; 2017a .

World Health Organization. Indonesia statistics summary (2002 - 2017), Global Health Observatory. Geneva: World Health Organization; $2017 b$.
World Health Organization. WHO child growth standards and the identification of severe acute malnutrition in infants and children: a joint statement by the World Health Organization and the United Nations Children's Fund. Geneva: World Health Organization; 2009.

Zeballos JL, Meli R, Vilchis A, Barrios L. The effects of volcanoes on health: preparedness in Mexico. World Health Stat Q 1996;49:204-208. 